\title{
On the issue of formation the air noise component at workplaces of the diesel locomotives crews
}

\author{
Ivan Yaitskov ${ }^{1, *}$ \\ ${ }^{1}$ Rostov State Transport University, 2, Rostovskogo Strelkovogo Polka Narodnogo Opolcheniya sq., \\ Rostov-on-Don, 344038, Russia
}

\begin{abstract}
The article is devoted to the general acoustic system of the diesel locomotives which is a combination of the diverse noise and vibration sources creating the increased levels of the sound pressure in the workplaces of the machinists and locomotive crews. Factually, the sound field at the calculated points is created by the simultaneous action of the air and structural noise component sources. It is included the emitters to the sources of the air noise component which inboard the body structures and, accordingly, emit sound energy into the closed air volumes. And it is the sources which are set externally in particular the "wheel-rail" subsystems. It can be assumed that among the internal sources the maximum sound power is radiated by the power system namely by the internal combustion engines. For different types of the diesel locomotives, the setting of the internal combustion engines has significant differences to the work places of the locomotive crews. Therefore, this article considers four computational schemes for the diesel locomotive, obtains the analytical dependences of the sound pressure levels and reduces to the convenient form for engineering calculations at the design stage of the research objects. To reduce the noise source of the internal combustion engine while it is appearing in the conditions of the machine-building processes is almost impossible. Moreover, the main practical and technological feasible ways are to choose sound-absorbing materials and achieve sound insulation based on the existing sanitary noise standards.
\end{abstract}

\section{Introduction}

The derivation of the dependencies of the air noise component levels in the cabin of the locomotives is created by the sound emission of the internal combustion engine which is located under the soundproof hood and based on the fact that the source acts on the five elements of the enclosure of the cabin through the air environment [1-14]. For diesel locomotives, it is calculated the schemes which are shown in Fig. 1-4; the noise sources (power system, high-voltage chamber, cooler cold-storage, etc.) inboard the body structure and form the sound field in the cabin due to the sound energy passing through relevant element of the cabin enclosure.

\footnotetext{
*Corresponding author: yia@rgups.ru
} 


\section{Object and research methods}

It is known that the diesel locomotives distinguish for cargo passenger, universal (cargopassenger and maneuver-export), shunting and industrial. The diesel locomotives are divided into wagon or closed (main diesel locomotives) and hood type (shunting locomotives). Therefore, it is the classification according to the number of sections: one-section, twosection and multi-section.

The crew of the diesel locomotive consists of the body, the main frame and bogies. On the main frame of the locomotive it is placed the power and auxiliary equipment of the diesel locomotive. The main frame transmits longitudinal traction and braking forces from the wheel sets to the rolling stock. The body and the cabin are also placed on the frame and it protects the equipment and the locomotive crew from external influences.

The construction of the wagon-type body forms the engine compartment with internal passages for servicing the power plant and auxiliary equipment; and the hood type body covers the locomotive equipment with hood and provides the access from the outside doors. For the passage of the service person and workers of the locomotive brigades, the locomotives with hood body are equipped with side (on both sides) and end (at the ends of the frame) platforms. Some series of the locomotives with the back wall of the cabin and the wall of the high-voltage chamber on one side, and the shaft of the cooling device or the wall of other equipment from the opposite side have the covered platform. In the covered platform it is located the auxiliary equipment and devices for monitoring its operation.

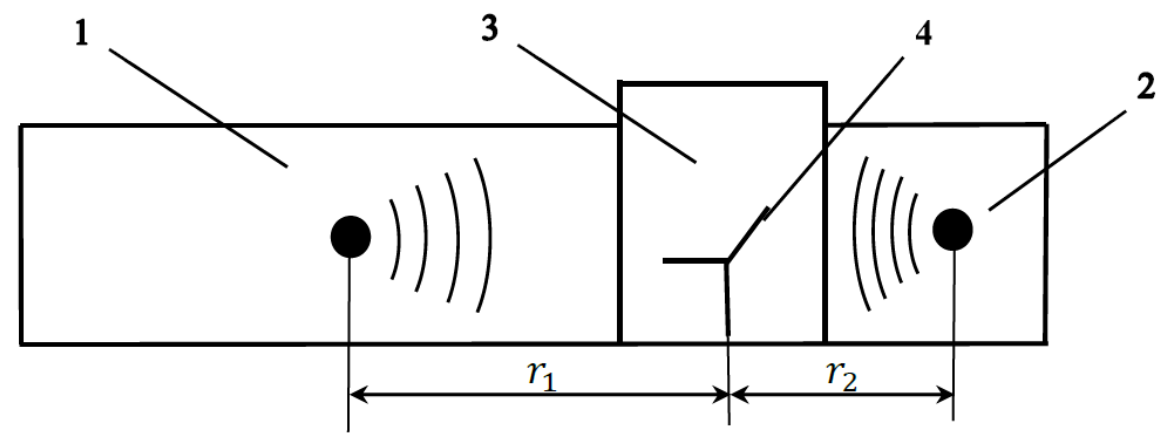

Fig. 1. Scheme of the hood type body of the shunting and maneuvering and removal diesel locomotives: 1 - engine room; 2 - high-voltage (hardware) camera; 3 - driver's cab; 4 - driver's workplace.

For all presented schemes of the diesel locomotives, the noise levels in the driver's cab should be calculated by the formula

$$
L=L_{P}+10 \lg \left(\frac{\chi_{\mathrm{M}}}{2 \pi r^{2}}+\frac{4 \psi_{i}}{B_{i}}\right)-3 h_{\text {part }}+10 \lg \frac{4 \psi_{k} S_{\text {part }}}{B_{k}},
$$

where $L_{P}$ - sound power levels in a room adjacent to the operator's cab, $\mathrm{dB}$;

$\chi_{\mathrm{M}}-$ correction for the noise field of the noise source, which is near to the enclosing surfaces;

$\psi_{i}$ - coefficient of diffuseness of the room with a noise source;

$\psi_{k}$ - coefficient of diffusion of the driver's cab;

$S_{\text {part }}$ - the area of the partition (the corresponding wall of the cabin), $\mathrm{m} 2$;

$r$ - distance from the center of the noise source to the driver's seat, $\mathrm{m}$;

$3 \mathrm{~h}_{\text {part }}$ - Sound insulation of the partition, $\mathrm{dB}$;

$B$ - constant of the relevant compartment, chamber or cabin, $\mathrm{m} 2$.

The circuit in Fig. 1 is characterized by the fact that the sound field in the cabin is formed by the transmitted sound energy through the back wall from the engine room and the front 
wall from the high-voltage (hardware) chamber, and the presence of the sound-insulating hood of the internal combustion engine.

The noise levels in the cabin created by the engine room are determined as follows

$$
\begin{aligned}
L_{k 1}=L_{P_{\mathrm{A}}}+10 \lg \left(\frac{\chi_{\mathrm{A}}}{s_{\text {hood }}}+\right. & \left.\frac{4 \psi_{\text {hood }}}{B_{\text {hood }}}\right)-3 \mathrm{~h}_{\text {part }}+10 \lg \frac{S_{\text {hood } 1}}{\chi_{\text {hood }}}+10 \lg \left(\frac{\chi_{\mathrm{A}}}{2 \pi r_{1}^{2}}+\frac{4 \psi_{1}}{B_{1}}\right)- \\
& -3 \mathrm{~h}_{\text {part } 1}+10 \lg \frac{4 \psi_{k} S_{\text {part }}}{B_{k}},
\end{aligned}
$$

where $L_{P_{\text {д }}}-$ sound power levels of the engine, $\mathrm{dB}$;

$3 \mathrm{~h}_{\text {part }}$ - soundproofing of the hood, $\mathrm{dB}$;

$3 \mathrm{~h}_{\text {part } 1}$ - soundproofing of the back wall of the cabin, $\mathrm{dB}$.

The noise levels in the cabin created by a high-voltage (hardware) camera are determined by the formula

$$
L_{k 2}=L_{P_{\mathrm{B}}}+10 \lg \left(\frac{\chi_{\mathrm{B}}}{2 \pi r_{2}^{2}}+\frac{4 \psi_{2}}{B_{2}}\right)-3 h_{\text {part } 2}+10 \lg \frac{4 \psi_{k} S_{\text {part } 2}}{B_{k}}
$$

The noise levels in the driver's cab for the circuit in Figure1 are determined by the energy summation

$$
L_{k(1)}=10 \lg \left(10^{0,1 L_{k 1}}+10^{0,1 L_{k 2}}\right)
$$

a)

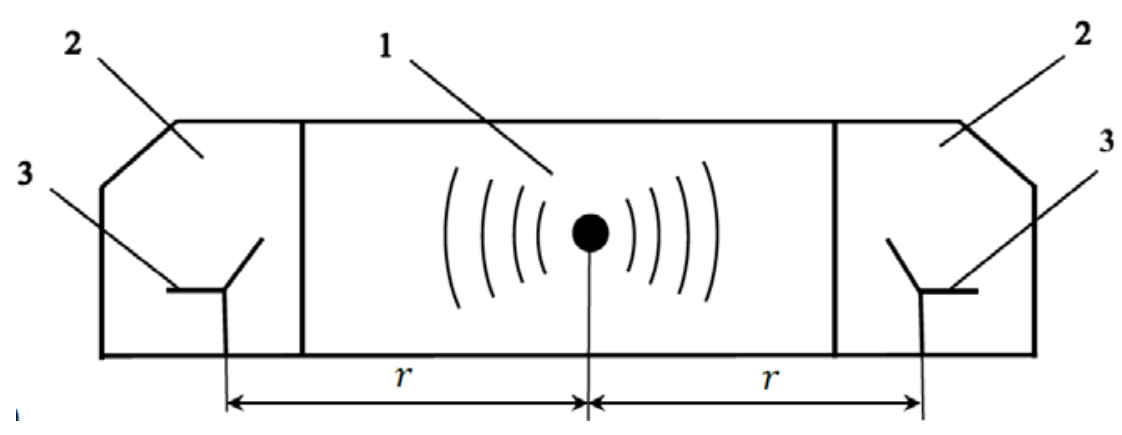

b)

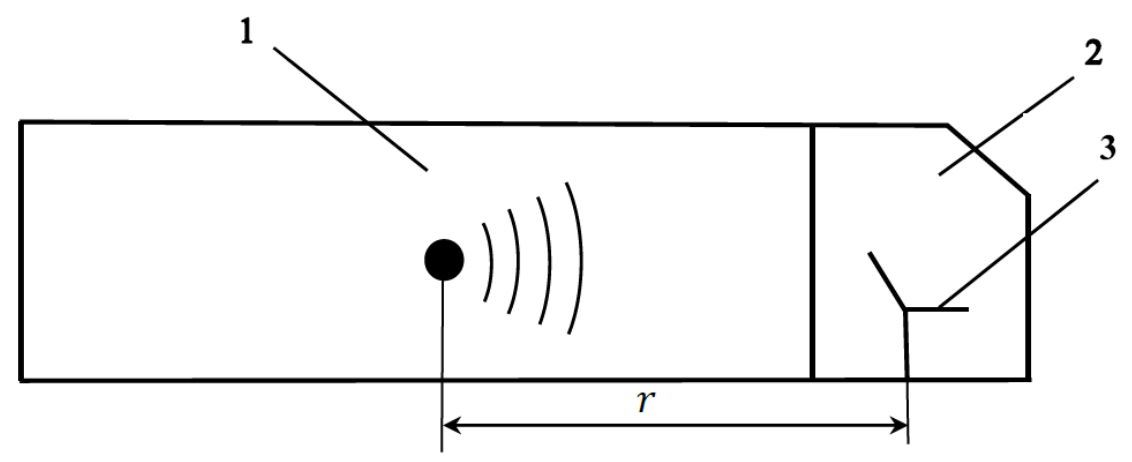

Fig. 2. Scheme of the car body type of the main single-section passenger (a) and two-section cargo (b) locomotives: 1 - engine room; 2 - driver's cab; 3 - driver's workplace

According to the configuration of the locomotive according to the scheme in Fig.2, it can be assumed that the noise levels in the cabins are determined by the sound energy in the 
engine room passing through the back walls. As the sound field in the engine room is determined by different noise sources, it is advisable to take the experimentally measured sound pressure levels and to recalculate them into sound power levels as initial data.

Then the noise levels in the driver's cabs are defined as

$$
L_{P_{k}}=L_{P_{1}}+10 \lg \left(\frac{\chi_{\mathrm{M}}}{2 \pi r^{2}}+\frac{4 \psi_{1}}{B_{1}}\right)-3 h_{\text {part }}+10 \lg \frac{4 \psi_{k} S_{\text {part1 }}}{B_{k}} .
$$

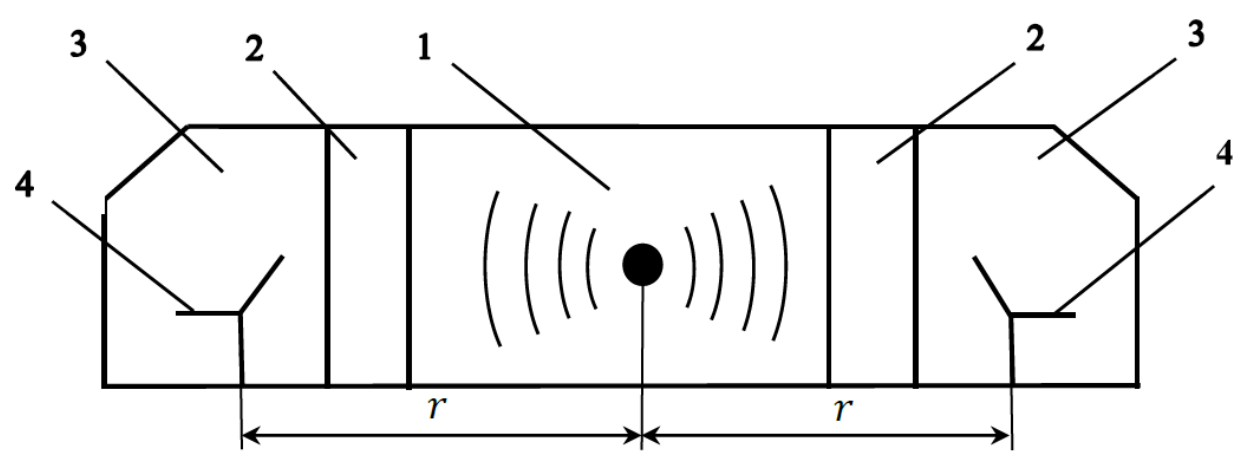

Fig. 3. Scheme of the car body type of the main single-section passenger and cargo-and-passenger locomotives: 1 - engine room; 2 -covered platform; 3 - driver's cab; 4 - driver's workplace.

The difference between the circuits in Fig. 3 and the circuit in Fig.e2 is that the sound energy in the engine room penetrates into the driver's cabins through the covered platform. Assuming that the areas of the covered platforms ' partitions between the engine room and the back wall of the cabin are the same, we obtain the following dependence of the noise levels in the cabin

$$
L_{P_{k}}=L_{P_{1}}+10 \lg \left(\frac{\chi_{\mathrm{M}}}{2 \pi r^{2}}+\frac{4 \psi_{1}}{B_{1}}\right)-3 h_{\text {part } 1}+10 \lg \frac{4 \psi_{\mathrm{T}} S_{\text {part }}}{B_{\mathrm{T}}}-3 h_{\text {part } 2}+10 \lg \frac{4 \psi_{k} S_{\text {part }}}{B_{k}}
$$

where $B_{\mathrm{T}}-$ constant of the covered platform, $\mathrm{m} 2$.

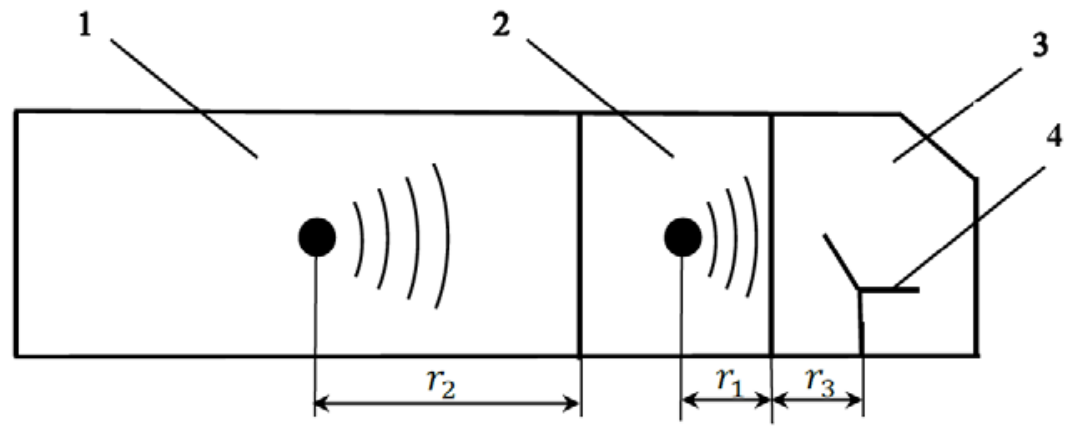

Fig. 4. Scheme of the car body type of the main single-section passenger and cargo-and-passenger locomotives: 1 - engine room; 2 -covered platform; 3 - driver's cab; 4 - driver's workplace.

For the circuit in Fig. 4, it is characteristic that the noise levels in the cabin are formed by the sound field in the compartment of the high-voltage (hardware) chamber and the covered platform, the sound field in which is formed directly by the camera radiation $\left(L_{P_{1}}\right)$ and by the sound energy passing into the high-voltage (hardware) camera from the engine room $\left(L_{P_{2}}\right)$ 


$$
\begin{gathered}
L_{P_{1}}=L_{P}+10 \lg \left(\frac{\chi_{\mathrm{M}}}{2 \pi r_{1}^{2}}+\frac{4 \psi_{2}}{B_{2}}\right), \\
L_{P_{2}}=L_{P}+10 \lg \left(\frac{\chi_{\mathrm{M}}}{2 \pi r_{2}^{2}}+\frac{4 \psi_{1}}{B_{1}}\right)-3 h_{\text {part } 1}+10 \lg \frac{4 \psi_{2} S_{\text {part }}}{B_{2}},
\end{gathered}
$$

where $3 h_{\text {part } 1}$ - sound insulation of the partition between the engine room and the separation of the high-voltage (hardware) camera and the covered platform, $\mathrm{dB}$.

The sound power levels of the separation of the high voltage chamber and the covered platform are defined as

$$
L_{P_{\Sigma}}=10 \lg \left(10^{0,1 L_{P 1}}+10^{0,1 L_{P 2}}\right)
$$

and the noise levels as

$$
L_{k}=L_{P_{\Sigma}}+10 \lg \left(\frac{\chi_{\mathrm{M}}}{2 \pi r_{3}^{2}}+\frac{4 \psi_{2}}{B_{2}}\right)-3 h_{\text {part } 2}+10 \lg \frac{4 \psi_{k} S_{\text {part }}}{B_{k}},
$$

where $3 \mathrm{~h}_{\text {part2 }}$ - soundproofing of the back wall of the cabin, $\mathrm{dB}$.

For all computational schemes, the values of the coefficients $\chi_{\mathrm{M}}$ and $\psi$ are taken from the obtained data [5]. Particularly, the correction to the near sound field can be taken equal to1 $\left(\chi_{\mathrm{M}}=1\right)$, because the relation $r / l_{\max } \geq 3$, where is the maximum dimensions of the source, $\mathrm{m}$. form

The diffusivity coefficient $\psi$ for the calculated circuit data is reduced to the following

$$
\psi=\frac{1-1,3 \alpha_{i}}{1-\alpha_{i}},
$$

where $\alpha_{i}$-the sound absorption coefficient of the relevant compartment.

For a cabin in which it is necessary to provide sound-absorbing structures for $\alpha>0,6$, we can assume $\psi=0,55$.

There is the sound-absorbing difference of the sound-insulating elements in the main body structure such as the hoods of internal combustion engines and partitions between the relevant compartments of the body and the cabin. Then it is necessary to consider the correction of the elements with reduced sound insulation (first of all, glazing elements). In this case, the sound insulation is defined as

$$
3 И=3 И_{0}-10 \lg \left[S_{0}+\sum_{1}^{n} S_{i} 10^{0,1\left(3 \mathrm{\Lambda}_{0}-3 \mathrm{\Lambda}_{i}\right)}\right]-10 \lg S_{i},
$$

where $S_{0}$ and $3 \mathrm{~h}_{0}$ - total area $(\mathrm{m} 2)$ and sound insulation $(\mathrm{dB})$ of the basic design; $S_{i}$ and $3 h_{i}$ - area $(\mathrm{m} 2)$ and sound insulation $(\mathrm{dB})$ of the elements with reduced sound insulation.

\section{Conclusions}

The obtained dependencies consider the parameters of the noise sources, their scheme relatively to the workplace of the locomotive brigades, the geometric and physic-mechanical parameters of the elements of the diesel locomotive body and the driver's cabs. The analytical expressions are convenient for engineering calculations at the design stage of the locomotives and enable to evaluate the compliance of the calculated noise levels with sanitary standards and prove ways for reducing noise levels on this basement. 


\section{References}

1. A. . I.A. Yaitskov, T.A. Finochenko, A.N. Chukarin, Identification of production factors affecting the working conditions of locomotive crews of diesel locomotives and locomotives, Engineering Don Bulletin, v.4 URL: ivdon.ru/en/magazine/archive/n4y2017/4438

2. I.A. Yaitskov, N.Ch. Chukarin, T.A. Finochenko, Theoretical Research of Noise and Vibration Spectra in Cabins of Locomotive and Diesel Shunting Locomotive, International Journal of Applied Engineering Research, v.12(21), pp.1072410730(2017)

3. I.A. Yaitskov, Theoretical study of the air component of the noise of power plants of transport vehicles, Internet-journal "Naukovedy", v.6(6)(2017) https://naukovedenie.ru/PDF/35TVN617.pdf (access is free)

4. I.A. Yaitskov, S.A. Razdorsky, On the calculation of the vibrations and noise spectra of the thin-walled shells on the example of the power plant hoods and in the abrasive bodywork processing of the welded joints, International scientific periodical "Modern fundamental and applied researches", v.4(27),pp.191-196(2017)

5. L.P. Borisov, Soundproofing in mechanical engineering (M.:Mechanical Engineering, 1990)

6. S.F. Podust, A.N. Chukarin, I.V. Boguslavsky, The basics of the vibroacoustic calculations of the domestic electric locomotives, (Rostov n/D: Publishing center of DSTU, 2013)

7. V.P. Sergienko, S.N. Bukharov, I.V. Kolesnikov, Yu.V. Pronnikov, A.P. Sychev, A.N. Chukarin, Reduction of noise and vibration of vehicles, (M.: Mechanical Engineering, 2014)

8. N.I. Ivanov, Fighting noise and vibrations on track and construction machines (M.: Transport, 1987)

9. I.V. Kolesnikov, S.F. Podoust, S.S. Podoust, A.N. Chukarin, The ways of noise and steepness of the revolution when designing, production and operation of the railway rolling stock (M.: VINITI RAS, 2015)

10. Yu.V. Pronnikov, Modeling the structural component of noise in the cabs of rolling stock drivers, Vestnik of the RSTU, v.3, pp.64-68(2010)

11. Yu.V. Pronnikov, On the calculation of the noise component in the cabs of the rolling stock drivers created by the vibration of the glazing elements, Transport. Security. Logistics: Intern. Scientific - practical. Conf., pp.8-14(2010)

12. L.G. Balishanskaya, L.F. Drozdova, N.I. Ivanov, Technical acoustics of transport vehicles: Reference book (St. Petersburg: Polytechnic, 1992)

13. N.I. Ivanov, B.A. Krishnevsky, Analysis of the soundproof cabins efficiency of the selfpropelled machines, Struggle against noise and harmful vibrations in construction, L.: Leningr. house n.t. propaganda, pp.45-51(1982)

14. N.I. Ivanov, G. Kurzev, The Théor and the Structure of the Transport Machine Noise Reduction, Unikeller Conference, Zürich, p.4(1989) 